\title{
Parasite communities in three sympatric flounder species (Pleuronectiformes: \\ Paralichthyidae)
}

\section{Ana J. Alarcos \& Juan T. Timi}

\section{Parasitology Research}

Founded as Zeitschrift für

Parasitenkunde

ISSN 0932-0113

Volume 110

Number 6

Parasitol Res (2012) 110:2155-2166

DOI 10.1007/s00436-011-2741-5

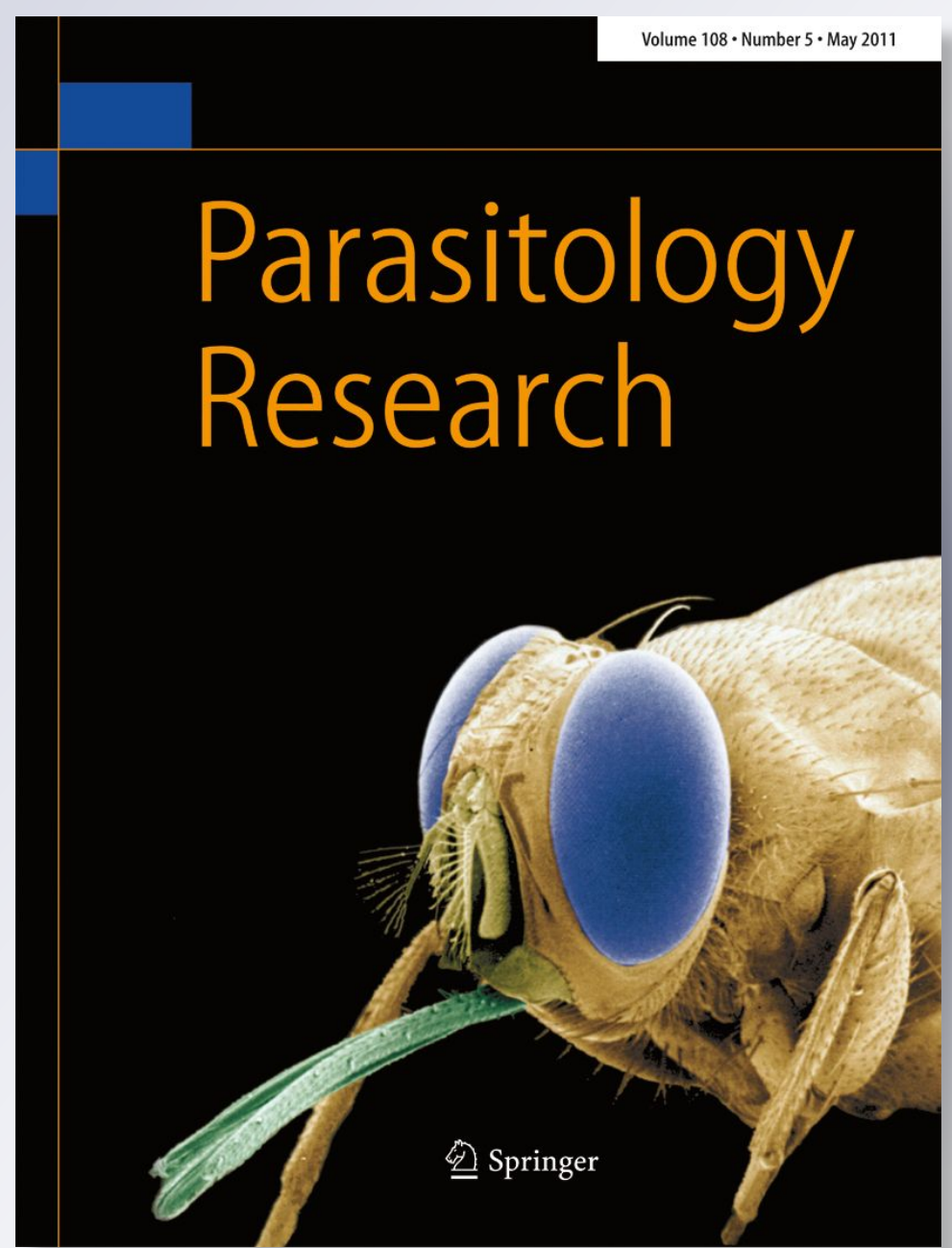

望 Springer 
Your article is protected by copyright and all rights are held exclusively by SpringerVerlag. This e-offprint is for personal use only and shall not be self-archived in electronic repositories. If you wish to self-archive your work, please use the accepted author's version for posting to your own website or your institution's repository. You may further deposit the accepted author's version on a funder's repository at a funder's request, provided it is not made publicly available until 12 months after publication. 


\title{
Parasite communities in three sympatric flounder species (Pleuronectiformes: Paralichthyidae)
}

\author{
Similar ecological filters driving toward repeatable assemblages
}

\author{
Ana J. Alarcos • Juan T. Timi
}

Received: 17 June 2011 / Accepted: 26 November 2011 / Published online: 14 December 2011

(C) Springer-Verlag 2011

\begin{abstract}
The relative role of host phylogeny and ecology on parasite community structure is analyzed in three sympatric paralichthyids from Argentine waters: the carcinophagous Xystreurys rasile and the piscivorous Paralichthys isosceles and P. patagonicus. Their relatedness, inherited ecological and physiological traits and shared past histories should result in certain similarities in their parasite assemblages. With this as our null hypothesis, we focused on the effects of measurable traits (size, age and diet) across fish species, with departures from a general pattern being interpreted as a consequence of ecological filters preventing homogeneous infections. The percentage of individuals/species that host-specific parasites contributed to each component community, as well as their effect on similarity of assemblages within/across host species, showed that they were not important contributors to abundance, richness and similarity, being irrelevant for the repeatability within component communities and across fish species as a phylogenetically related group. To minimize the effect of variables other than diet or trophic level only trophically transmitted nonspecific parasites were included in further analyses. After controlling for fish size, the congeneric host species harboured assemblages significantly different from those found in X. rasile, but were similar to each other because of their shared high trophic levels. Assemblages of equivalent structure harboured by fish with different age-size relationships showed that these variables seem to act at dissimilar
\end{abstract}

\footnotetext{
A. J. Alarcos $(\bowtie) \cdot$ J. T. Timi

Laboratorio de Parasitología,

Instituto de Investigaciones Marinas y Costeras (IIMyC),

Consejo Nacional de Investigaciones Científicas y Técnicas

(CONICET), Facultad de Ciencias Exactas y Naturales,

Universidad Nacional de Mar del Plata,

Funes 3350,

7600 Mar del Plata, Argentina

e-mail: anajulia_alarcos@yahoo.com.ar
}

rates on different features of the parasites assemblages. Indeed, age affected mainly the parasite abundance, whereas body size influenced mostly species richness. In conclusion, similar ecological filters produce analogous infections across host species driving towards homogeneous parasite communities.

\section{Introduction}

Fish parasite assemblages are highly complex and dynamic ecological systems resulting from the interaction of evolutionary and ecological processes acting together at multiple levels. The discernment between these factors is not always straightforward (Desdevises et al. 2003), and these characteristics make the recognition of recurrent patterns in community structure difficult (Poulin 2007).

The relative role of phylogeny and host ecology as drivers of parasite community structure has been a matter of debate for many years among parasite ecologists (Poulin 1995; Poulin and Rohde 1997; Morand and Poulin 2003; Poulin et al. 2011). The host phylogeny is expected to have an influence on the structure of parasite assemblages since related host species can harbour related parasites inherited from their common ancestors through cospeciation (Vickery and Poulin 1998; Poulin and Morand 2004). For this reason, many researchers have applied comparative methods that control for host phylogeny to disentangle both variables and uncover the importance of host ecology (Poulin 1995; Poulin and Rohde 1997; Sasal et al. 1997; Luque et al. 2004; Luque and Poulin 2008). However, it has been argued recently that the phylogenetic position of a species encompasses much of its history, as well as its ecological and immunological features, and is therefore a much better predictor of species richness acquired 
over evolutionary time by a particular host lineage than any ecological variable (Poulin et al. 2011).

The present study on the parasites of three sympatric and closely related species, was chosen from this perspective in order to "neutralize" phylogenetically inherited ecological (i.e., habitat, general shape) and physiological characteristics as well as shared past history (i.e., biogeographic area of origin). A certain degree of similarity in their parasite assemblages should be expected for related host species (Poulin and Rohde 1997; Luque et al. 2004; Luque and Poulin 2008), especially for those hosts with similar ecology (Muñoz et al. 2006; Marques et al. 2011), constituting a null hypothesis through which to focus on the effect of measurable differences, such as size, age and diet between fish species. Thus, any departure from a general pattern could be interpreted as the consequence of ecological filters preventing a homogeneous infection across host species.

Among host ecological traits that have been identified as key determinants of species assembly rules in fish parasite communities are size and age, habitat, diet, trophic level, schooling behavior, population size and density, depth distribution and geographical range (Poulin and Morand 2000; Luque et al. 2004; Bagge et al. 2004; Pérez-del Olmo et al. 2008; Luque and Poulin 2008; Timi et al. 2011). However, the available knowledge about the relative magnitude of different fish characteristics as drivers of the structure of parasite assemblages shows little consistency (Poulin and Morand 2004), with contingent, rather than recurrent, patterns being the general rule (Poulin 2007; Luque and Poulin 2008). This fact should be a consequence of the effect of environmental characteristics and trophic webs at local scales, regardless of the traits of the host species (Marcogliese 2001, 2002; Luque et al. 2004; Luque and Poulin 2008; Aguirre-Macedo et al. 2007), as well as to the parasite guild under study, because ecto- or endoparasites can respond differently to either environmental or host related variability (Luque and Poulin 2008; Timi et al. 2010a; Marques et al. 2011).

In shelf waters off Buenos Aires Province, Argentina, fish parasite assemblages are dominated by trophically transmitted larval helminths in all host species so far studied, with a suit of species of low host specificity being widely distributed and ubiquitous among fish hosts (Timi 2007; Lanfranchi et al. 2009; Timi and Lanfranchi 2009; Rossin and Timi 2010; Vales et al. 2011). These parasites indiscriminately infect paratenic hosts, in which they can live for long periods, and some of them can be transmitted from one paratenic host (prey) to others (predators), thus persisting in the food web. These characteristics make them potentially available for any fish host, independently of its trophic level. However, Timi et al. (2011) recently demonstrated that not all host species in this study area harbour the same number and type of parasites, reflecting the existing differences in their ecological characteristics, among which the trophic level featured as the main explanatory factor for the similarity of parasite assemblages across fish species. Among the species studied, two sympatric paralichthyids, Xystreurys rasile (Jordan, 1891) and Paralichthys isosceles Jordan, 1891 varied in the species composition of their parasite assemblages, attributable to their different trophic levels (Timi et al. 2011). These two species differ in their feeding habits, with $X$. rasile preying exclusively on benthic invertebrates and $P$. isosceles also including a high proportion of fishes (Díaz de Astarloa and Munroe 1998; Cousseau and Perrotta 2004). Here, we include a third paralichthyid, Paralichthys patagonicus Jordan, 1889, caught in the same region, a species with similar trophic habits to those of P. isosceles (Díaz de Astarloa and Munroe 1998), to test whether two sympatric species with similar habitat and diet display similar assemblages of nonspecific parasites in terms of both abundance and species composition, as well as in relation to their infracommunity descriptors. Previous studies on parasites of these flounders were mainly taxonomic and focused on particular parasite groups in Argentina (Szidat 1961; Incorvaia and Díaz de Astarloa 1998; Suriano and Labriola 1998, 1999; Alarcos and Timi 2011) and Brazil (Luque and Tavares 2007; Felizardo et al. 2009a, b, 2010, 2011).

The aim of this paper is, therefore, two-fold: first, to describe for the first time the parasite communities of three sympatric paralichthyids, $X$. rasile, $P$. isosceles and P. patagonicus, and second, to analyze their relationships with the feeding habits and trophic levels of the fishes, in order to determine if similar ecological filters produce analogous infections across host species driving towards homogeneous parasite communities.

\section{Materials and methods}

A total of 150 paralichthyid flounders were examined for parasites. Fish were caught by trawl in waters off Necochea, Argentina $\left(38^{\circ} 52^{\prime} \mathrm{S}, 58^{\circ} 10^{\prime} \mathrm{W}\right)$ and landed at Puerto Quequén by commercial fishermen (Table 1). Fish were either kept fresh or deep frozen at $-18^{\circ} \mathrm{C}$ until examination. After thawing flounders were measured for total length $(\mathrm{cm})$ and sexed. Body surface, gills, branchial and body cavities, viscera (stomach, intestine, liver, gall bladder, spleen, heart, gonads and mesenteries), swim bladder, kidneys and musculature were examined with the aid of a stereomicroscope. Fins were examined only for specimens of $P$. patagonicus.

Fish lengths were compared between samples by means of a one-way ANOVA (Zar 1996). The prevalence and mean abundance were calculated for each parasite species in each sample following Bush et al. (1997).

Host-specific parasites and those belonging to general known to display a certain degree of host specificity (those described from the host species examined and not reported from other fishes) were identified with reference to the 
Table 1 Composition of samples of three species of paralichthyid flounders, caught off Necochea Argentina

\begin{tabular}{llllll}
\hline Species & $N$ & Date of capture & Total length \pm SD & Maximum size (cm) $)^{\text {a }}$ & Mean \% of maximum size \pm SD \\
\hline Xystreurys rasile & 48 & 22 May 2009 & $29.26 \pm 2.64$ & Males: 39, females: 43 & $70.84 \pm 6.91$ \\
Paralichthys isosceles & 51 & 22 May 2009 & $27.95 \pm 2.11$ & Males: 32, females: 38 & $80.95 \pm 7.44$ \\
Paralichthys patagonicus & 51 & 29 September 2010 & $35.20 \pm 2.64$ & Males: 48, females: 62 & $65.50 \pm 9.43$ \\
\hline
\end{tabular}

${ }^{a}$ Maximum size recorded for the species, taken from Cousseau and Perrotta (2004) and Froese and Pauly (2010)

relevant bibliography. Their numerical importance was measured as the percentage of individuals and species they contributed to the total abundance and species richness, respectively, of each component community, as well as their contribution to similarity in parasite assemblages within and across host species. For the last analyses, similarity percentages (SIMPER; Clarke 1993) between parasite assemblages were calculated on values of abundance among all possible pairs of individual fish (infracommunities) within and between host species and expressed as averaged similarity, for all parasite species, and after excluding sequentially the host-specific and the nonspecific gut parasites. SIMPER and subsequent multivariate statistical procedures on community data were implemented in PRIMER package V6 (Clarke and Gorley 2006; Clarke and Warwick 2001) and PERMANOVA+for PRIMER package (Anderson et al. 2008).

In order to minimize the effect of variables other than diet or trophic level, the following restrictions were made to the data set, to avoid the effect of host phylogeny, if any, on parasite communities. Only nonspecific parasites were included in comparative analyses, focusing on the guild of trophically transmitted helminths, i.e., metacercariae of actively penetrating trematodes were excluded. As samples of $X$. rasile and $P$. isosceles were obtained in a single catch, it is assumed that both species are exposed to the same set of infective stages. Samples of $P$. patagonicus were caught 1 year later and during a different season (spring). As endohelminths of the gut lumen are frequently relatively short-lived (Lester and MacKenzie 2009), this guild of parasites was excluded prior to comparative analyses. The same geographical origin of samples also precludes any possible spatial heterogeneity in the distribution of infective stages. The possible effect of host size was taken into account by including this factor as a covariable in comparative analyses.

In the case of host-specific parasites, similarity percentages (SIMPER) were calculated to identify typical and discriminator species of trophically transmitted and long-lived larval helminths. This analysis was made to determine if hostspecific parasites characterized or distinguished between parasites assemblages: "characterized" if they were "typical species" contributing substantially to the average similarity and doing it consistently by displaying a high ratio between that contribution and its standard deviation, and "distinguished" if they were "discriminator species" contributing largely to the average dissimilarity and displaying a high ratio between that contribution and its standard deviation (Clarke and Gorley 2006). The Bray-Curtis index, which takes into account differences in abundance of each shared parasite species (Magurran 1988) was used as a similarity measure.

The differences in community structure were tested by means of a one-way permutational multivariate analysis of the variance (PERMANOVA) on parasite abundances. The structure of parasite infracommunities between samples $(1 \times 3$ factorial design, host species as fixed factors) was compared, testing for main effects after 9,999 permutations. Where differences were detected by PERMANOVA, pair-wise comparisons were used to determine which samples differed. Following Anderson et al. (2008) a permutation of residuals under a reduced model was used as the method of permutation. A sequential sum of squares (Type I SS) was applied because samples were unbalanced (different numbers of fish examined per sample) and because host size was introduced as a covariable (ANCOVA model). Fish length was included as a covariable because of the known effect of size/age on parasite burdens of fish. The Bray-Curtis index was used as a similarity measure. These procedures were repeated applying the Jaccard index as a similarity measurement, an index that uses binary presence-absence data (Magurran 1988) to compare species composition between samples. Since PERMANOVA is sensitive to differences in multivariate dispersion between groups (sensu homogeneity of variances, which can inflate Type 1 error even when centroids have identical locations), the same models were tested for differences in dispersion using the routine PERMDISP (Anderson et al. 2008). Dispersions were measured as distances to the centroids and each term in the analysis was tested using 9,999 permutations, with significant terms investigated using a posteriori pair-wise comparison with $t$-statistic (Anderson et al. 2008) between those pairs of samples showing significant differences with PERMANOVA.

For each individual fish the following community descriptors were calculated at infracommunity level: total abundance (the number of parasites per host, $N$ ), species richness $(S)$, Brillouin's index of diversity (HB) and BergerParker's index of dominance (BP) (Magurran 1988); the latter two indices were calculated only for those flounders harbouring two or more species. Infracommunity descriptors 
were compared between host species with univariate PERMANOVA and PERMDISP analyses, using Euclidean distances for the construction of similarity matrices.

\section{Results}

Mean host body lengths were significantly different between flounder species $\left(F_{2,146}=123.7 ; P<0.01\right)$, with all pairs of species showing differences in size $(X$. rasile- $P$. isosceles, $0.01<P<0.05$; both comparisons involving $P$. patagonicus, $P<0.01$ )

Only one specimen of $X$. rasile was found unparasitized, the rest of the hosts were parasitized by at least one of 26 parasite species (Table 2). Of these, metacercariae of Prosorhynchus australis found in the fins of $P$. patagonicus were excluded from further analyses because the fins of the other two host species were not examined.

Table 2 Prevalence $(P)$ and mean abundance $(\mathrm{Ma} \pm \mathrm{SD})$ of metazoan parasites in three species of paralichthyid flounders from the southwestern Atlantic

\begin{tabular}{|c|c|c|c|c|c|c|c|c|}
\hline \multirow[t]{2}{*}{ Parasite species } & \multirow[t]{2}{*}{ Stage } & \multirow[t]{2}{*}{ Site } & \multicolumn{2}{|c|}{ Xystreurys rasile } & \multicolumn{2}{|c|}{ Paralichthys isosceles } & \multicolumn{2}{|c|}{ Paralichthys patagonicu. } \\
\hline & & & $P$ & $\mathrm{Ma} \pm \mathrm{SD}$ & $P$ & $\mathrm{Ma} \pm \mathrm{SD}$ & $P$ & $\mathrm{Ma} \pm \mathrm{SD}$ \\
\hline \multicolumn{9}{|l|}{ Monogenea } \\
\hline $\begin{array}{l}\text { Neoheterobothrium paralichthyi Suriano et } \\
\text { Labriola, } 1999\end{array}$ & Ad & $\mathrm{Gi}$ & - & - & - & - & 17.65 & $0.24 \pm 0.59$ \\
\hline \multicolumn{9}{|l|}{ Digenea } \\
\hline Hemiuroidea gen. sp. & $\mathrm{Me}$ & St & - & - & - & - & 56.86 & $2.20 \pm 3.49$ \\
\hline Prosorhynchus sp. & $\mathrm{Me}$ & $\mathrm{Gi}$ & - & - & - & - & 13.73 & $0.47 \pm 2.02$ \\
\hline Prosorhynchus australis Szidat 1961 & $\mathrm{Me}$ & $\mathrm{Fi}$ & $\mathrm{Ne}$ & $\mathrm{Ne}$ & $\mathrm{Ne}$ & $\mathrm{Ne}$ & 64.71 & $5.53 \pm 7.33$ \\
\hline Derogenes varicus (Müller, 1784) & Ad & St-In & 37.50 & $1.29 \pm 2.29$ & 11.76 & $0.22 \pm 0.70$ & - & - \\
\hline Lecithochirium microstomum Chandler, 1935 & Ad & St & 10.42 & $0.17 \pm 0.56$ & - & - & - & - \\
\hline Aponurus laguncula Loos, 1907 & Ad & St & - & - & - & - & 23.53 & $0.94 \pm 0.28$ \\
\hline Paralichthytrema patagonicum Szidat, 1960 & Ad & GI & - & - & - & - & 7.84 & $0.08 \pm 0.27$ \\
\hline \multicolumn{9}{|l|}{ Cestoda } \\
\hline Scolex polymorphus Müller, 1784 & $\mathrm{Pl}$ & St-In & 45.83 & $4.42 \pm 9.39$ & 7.84 & $6.47 \pm 24.61$ & 54.90 & $10.35 \pm 27.08$ \\
\hline Nybelinia $\mathrm{sp}$ & $\mathrm{Pl}$ & St-In & 50.00 & $1.60 \pm 2.18$ & 58.82 & $6.08 \pm 9.02$ & 88.23 & $5.02 \pm 4.28$ \\
\hline Grillotia carvajalregorum (Carvajal et Rego, 1983) & $\mathrm{Pc}$ & $\mathrm{Me}$ & 56.25 & $5.04 \pm 9.75$ & 100 & $332.39 \pm 314.13$ & 100 & $167.22 \pm 198.00$ \\
\hline Unidentified larva & $\mathrm{Pl}$ & $\mathrm{Me}$ & 2.08 & $0.02 \pm 0.14$ & - & - & - & - \\
\hline Anonchocephalus argentinensis Szidat 1961 & Ad & In & 14.58 & $0.23 \pm 0.79$ & - & - & - & - \\
\hline \multicolumn{9}{|l|}{ Nematoda } \\
\hline Anisakis simplex (Rudolphi, 1809) s.l. & LIII & $\mathrm{Me}$ & - & - & - & - & 9.80 & $0.18 \pm 0.59$ \\
\hline Terranova galeocerdonis (Thwaite, 1927) & LIII & $\mathrm{Me}$ & - & - & - & - & 1.96 & $0.02 \pm 0.14$ \\
\hline Contracaecum sp. & LIII & $\mathrm{Me}$ & 12.77 & $0.21 \pm 0.62$ & 50.98 & $1.37 \pm 1.94$ & 39.22 & $0.61 \pm 1.15$ \\
\hline Pseudoterranova sp. & LIII & $\mathrm{Me}-\mathrm{Mu}$ & 2.08 & $0.06 \pm 0.43$ & 1.96 & $0.02 \pm 0.14$ & 17.65 & $0.25-0.63$ \\
\hline Hysterothylacium sp. & LIII & $\mathrm{Me}$ & 33.33 & $0.69 \pm 1.36$ & 37.25 & $0.63 \pm 0.92$ & 27.45 & $0.49 \pm 1.10$ \\
\hline Hysterothylacium aduncum (Rudolphi, 1802) & LIII & $\mathrm{Me}$ & 2.08 & $0.02 \pm 0.14$ & 11.76 & $0.12 \pm 0.33$ & - & - \\
\hline Ascarophis marina (Szidat 1961) & Ad & In & 2.08 & $0.02 \pm 0.14$ & - & - & - & - \\
\hline Cucullanus sp. & Ad & In & 27.08 & $0.50 \pm 0.92$ & - & - & - & - \\
\hline $\begin{array}{l}\text { Cucullanus bonaerensis Lanfranchi, Timi et } \\
\text { Sardella, } 2004\end{array}$ & Ad & In & 39.58 & $0.73 \pm 1.22$ & - & - & - & - \\
\hline Dichelyne pleuronectidis Yamaguti 1935 & Ad & In & - & - & 11.76 & $0.16 \pm 0.46$ & 60.78 & $2.06 \pm 3.15$ \\
\hline \multicolumn{9}{|l|}{ Acanthocephala } \\
\hline Corynosoma australe Johnston, 1937 & $\mathrm{Ju}$ & $\mathrm{Me}$ & 89.58 & $9.23 \pm 9.38$ & 92.16 & $14.69 \pm 20.55$ & 94.12 & $6.35 \pm 4.30$ \\
\hline Corynosoma cetaceum Johnston et Best, 1942 & $\mathrm{Ju}$ & $\mathrm{Me}$ & 2.08 & $0.04 \pm 0.29$ & - & - & 74.51 & $2.55 \pm 2.71$ \\
\hline \multicolumn{9}{|l|}{ Copepoda } \\
\hline Brasilochondria riograndensis Tatcher et Pereira, 2004 & Ad & Op & - & - & - & - & 5.88 & $0.06 \pm 0.24$ \\
\hline Acanthochondria sagitta Alarcos et Timi, 2011 & Ad & $\mathrm{Gi}$ & 2.08 & $0.06 \pm 0.43$ & - & - & - & - \\
\hline
\end{tabular}

Stages: $A d$ adult, $J u$ juvenile, $L I I I$ third-stage larva, $P c$ plerocercus, $P l$ plerocercoid; sites: $F i$ fins, $G I$ gills, $I N$ intestine, $M e$ mesenteries, $M U$ musculature, $O P$ operculum, St stomach; Ne not examined 
Parasites were unevenly distributed among flounder species, with $P$. patagonicus, $X$. rasile and $P$. isosceles harbouring 17, 17 and ten species, respectively (P. australis excluded). Only six species were common to all three flounders, with Grillotia carvajalregorum, Contracaecum sp., Hysterothylacium sp. and Corynosoma australe reaching high values of prevalence in all of them. Eight (excluding P. australis) species were found parasitizing exclusively P. patagonicus and seven exclusively in $X$. rasile, while all species found in $P$. isosceles were shared with one or both other species.

Parasites identified as host-specific were all at the adult stage, and comprised the copepod Acanthochondria sagitta, the cestode Anonchocephalus argentinensis and the nematodes Cucullanus bonaerensis and Cucullanus sp. in $X$. rasile, the nematode Dichelyne pleuronectidis in both Paralichthys spp. and the copepod Brasilochondria riograndensis, the monogenean Neoheterobothrium paralichthyi and the digenean Paralichthytrema patagonicum in P. patagonicus. This group made a small contribution to both total abundance (Fig. 1a) and species richness (Fig. 1b) in all three flounder species, while nonspecific parasites, especially

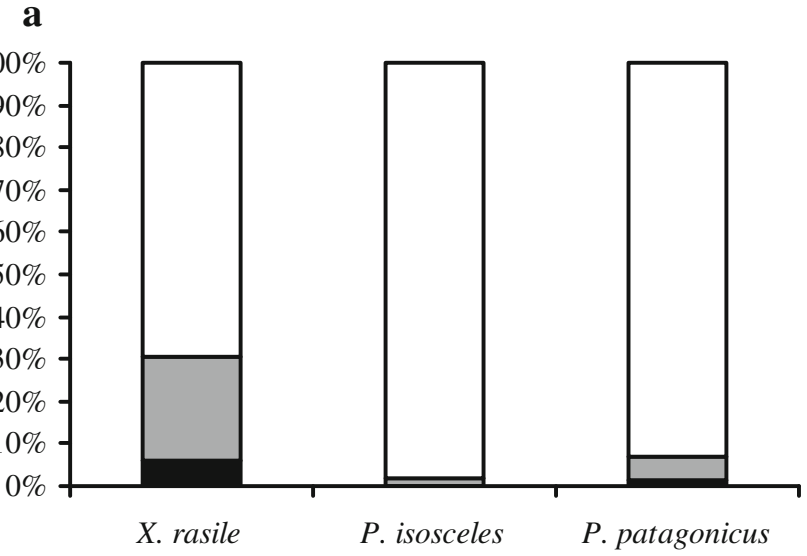

b

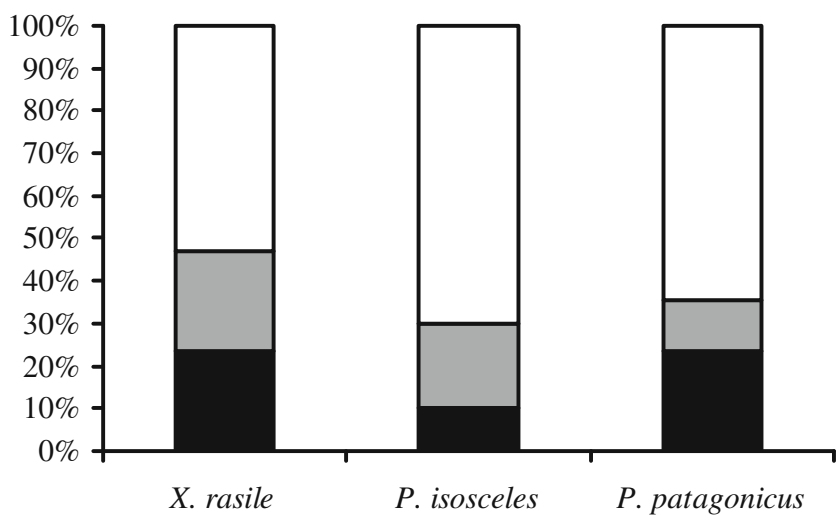

Fig. 1 Contributions of parasite guilds, expressed as percentages, to total abundance and (a) species richness (b) of parasite assemblages of three species of paralichthyid flounders. Black specific parasites, grey unspecific intestinal parasites, white unspecific larval non-intestinal parasites non-gut larval ones, were the dominant guild, especially in terms of abundance.

The influence of host-specific and gut parasites on similarity within (Fig. 2a) and between (Fig. 2b) host species was negligible when compared with that based on all species, similarities being mainly determined by non-gut nonspecific helminths. It is also noteworthy that host-specific parasites diminished similarity between infracommunities within host species.

The contribution of individual species of host-specific parasites, as well as of all of them together had little influence on the within host species infracommunity average similarity when compared with nonspecific parasites (Table 3). Also their effect on dissimilarity between host species was unimportant. Furthermore, D. pleuronectidis, the only host-specific parasite shared by two host species contributed more to dissimilarity between them than other species present in only one flounder (Table 3).

When only long-lived larval endohelminths were considered, species richness was more homogeneous across flounder species, being 10, 9 and 6 for $P$. patagonicus, $X$. rasile and $P$. isosceles, respectively. Excluding parasites with

a

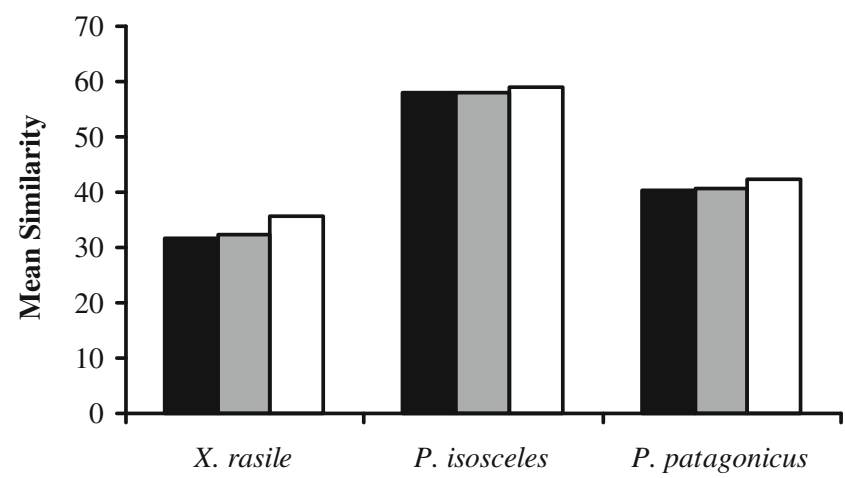

b

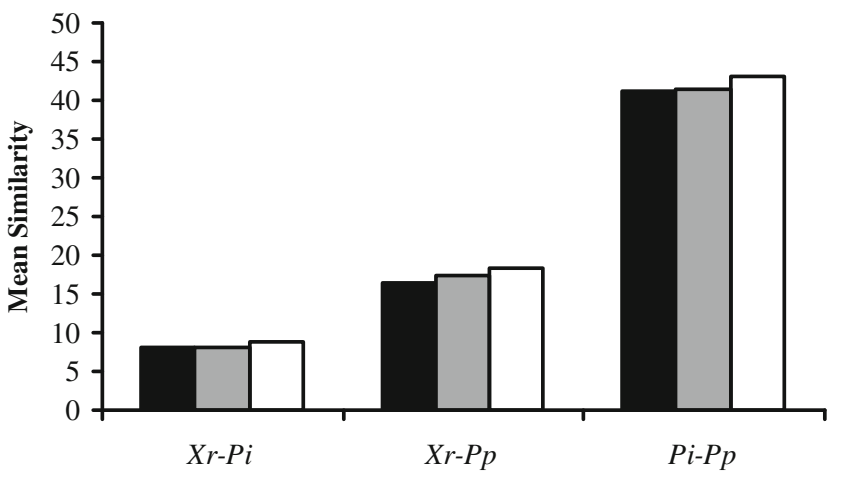

Fig. 2 Averaged Bray-Curtis similarity between pairs of infracommunities within (a) and between (b) three species of paralichthyid flounders. Black all parasites included, grey specific parasites excluded, white specific parasites and nonspecific intestinal parasites excluded. Xr Xysteurys rasile, $P$ i Paralichthys isosceles, $P p$ Paralichthys patagonicus 
Table 3 Breakdown of average similarity and dissimilarity of infracommunities of individual host-specific parasites and of species grouped in: total specific parasites, total nonspecific intestinal parasites and total nonspecific extra-intestinal parasites within and between three sympatric flounders into contributions from each species/group expressed as percentages

\begin{tabular}{|c|c|c|c|c|c|c|}
\hline & $X$. rasile & P. isosceles & P. patagonicus & $X r-P i$ & $X r-P p$ & $P i-P p$ \\
\hline C. bonaerensis & 3.15 & - & - & 0.35 & 0.81 & - \\
\hline Cucullanus sp. & 1.02 & - & - & 0.22 & 0.49 & - \\
\hline A. argentinensis & 0.37 & - & - & 0.11 & 0.25 & - \\
\hline A. sagitta & - & - & - & 0.03 & 0.06 & - \\
\hline D. pleuronectidis & - & 0.01 & 1.73 & 0.07 & 2.6 & 1.02 \\
\hline N. paralichthyi & - & - & 0.06 & - & 0.27 & 0.11 \\
\hline P. patagonicus & - & - & 0.01 & - & 0.05 & 0.03 \\
\hline B. riograndensis & - & - & 0 & - & 0.07 & 0.03 \\
\hline Total specific parasites & 4.54 & 0.01 & 1.8 & 0.78 & 4.6 & 1.19 \\
\hline Total nonspecific intestinal parasites & 14.64 & 0.23 & 2.24 & 5.36 & 9.22 & 6.38 \\
\hline Total nonspecific non-intestinal parasites & 80.82 & 99.76 & 95.96 & 93.86 & 86.18 & 92.43 \\
\hline
\end{tabular}

Xr Xystreurys rasile, Pi Paralichthys isosceles, Pp Paralichthys patagonicus

very low prevalence $(<5 \%)$ and probably accidental in some hosts different, these values were reduced to 9,5 and 5 .

SIMPER results on abundances of this group showed that P. isosceles was the most homogeneous species in terms of parasite community structure with both measurements of similarity, followed by $P$. patagonicus and finally $X$. rasile (Fig. 3a). The main contributor to similarity for $X$. rasile was C. australe and it did so consistently in inter-comparisons, as shown by the ratios between their contributions and standard deviations $>1$ (Table 4), although G. carvajalregorum and Nybelinia sp. were also important in contributing to similarity within this sample. On the other hand, G. carvajalregorum was the only typical species for both species of Paralichthys; this species, despite being a relevant contributor to within samples similarity, was also an important and consistent discriminator among all of them (Table 4).

Comparisons across host species showed the highest similarities between the two Paralichthys spp. when the quantitative Bray-Curtis was used as similarity measurement, but more equivalent values of similarity between species when presence only of parasite species was compared by means of the Jaccard index (Fig. 3b).

Results of both PERMANOVA analyses (Table 5) showed a strong effect of host size on the response variables, and therefore on the parasite community structure. The interaction of host length with host species shows that the nature of the relationship between the covariate and the multivariate response differs within different levels of the factor. Furthermore, taking into account the variations among samples due to host size, significant variability was detected among the parasite assemblages. Pair-wise tests between host species showed that there were significant differences between most pairs of samples (all $P<0.001$ ), except for both congeneric species when Bray-Curtis similarity was used $(P>0.05)$.
Dispersion of parasite infracommunities varied between flounder species in terms of their deviations from centroids, with significant variability observed for Bray-Curtis similarity

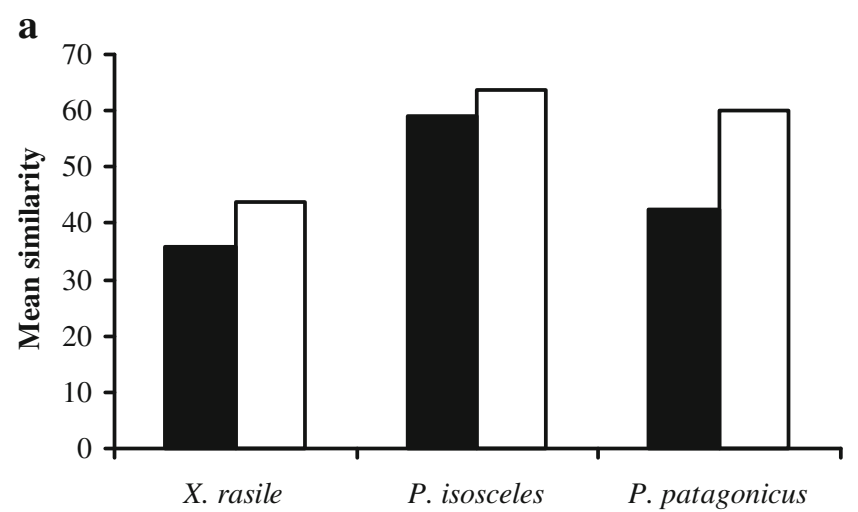

b

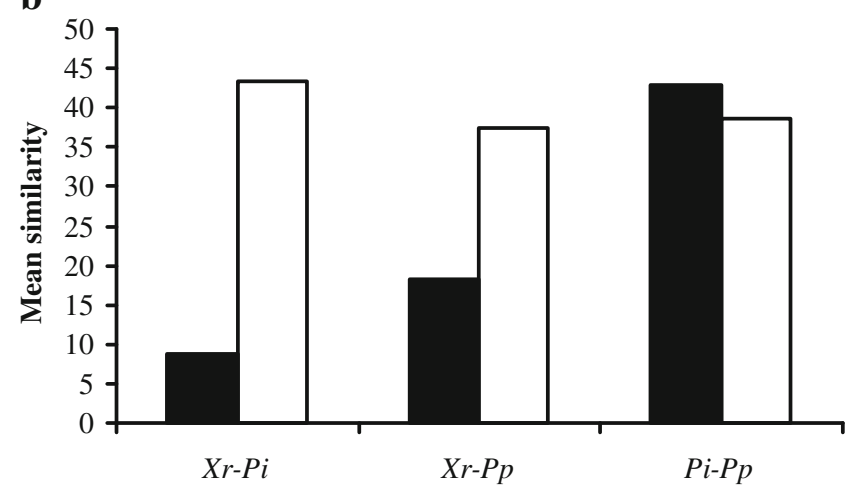

Fig. 3 Averaged similarity between pairs of infracommunities of nonspecific non-intestinal parasites within (a) and between (b) three species of paralichthyid flounders. Black Bray-Curtis similarity, white Jaccard similarity. Xr Xysteurys rasile, Pi Paralichthys isosceles, Pp Paralichthys patagonicus 
Table 4 Breakdown of average similarity and dissimilarity of infracommunities of individual host-specific parasites and of species grouped in: total specific parasites, total nonspecific intestinal parasites and total nonspecific extra-intestinal parasites within and between three sympatric flounders into contributions from each species/group expressed as percentages

\begin{tabular}{|c|c|c|c|c|c|c|}
\hline & $X$. rasile & P. isosceles & P. patagonicus & $X r-P i$ & $X r-P p$ & $P i-P p$ \\
\hline C. australe & 66.87 & 3.71 & 8.19 & 91.28 & 75.74 & 87.81 \\
\hline G. carvajalregorum & 20.63 & 95.93 & 87.92 & 6.52 & 9.25 & 5.7 \\
\hline Nybelinia sp. & 10.39 & - & 7.15 & 0.92 & 6.18 & 2.72 \\
\hline Hysterothylacium sp. & 1.93 & 0.09 & 0.21 & 0.57 & 1.16 & 0.71 \\
\hline Contracaecum sp. & 0.17 & 0.26 & 0.49 & 0.48 & 1.46 & 0.45 \\
\hline H. aduncum & - & 0.01 & - & 0.15 & 0.03 & 0.08 \\
\hline C. cetaceum & - & - & 2.32 & 0.05 & 0.45 & 0.15 \\
\hline Hemiuroidea gen. sp. & - & - & 1.79 & 0.02 & 2.64 & 1.18 \\
\hline Unidentified plerocercoid & - & - & 0.09 & 0.01 & 0.03 & - \\
\hline Pseudoterranova sp. & - & - & 0.03 & - & 2.79 & 1.09 \\
\hline A. simplex s.1. & - & - & - & - & 0.27 & 0.1 \\
\hline
\end{tabular}

Values for typical (average contribution to the total average similarity/standard deviation $>1$ ) and discriminator (average contribution to the total average dissimilarity/standard deviation $>1$ ); species are in bold

Xr Xystreurys rasile, Pi Paralichthys isosceles, Pp Paralichthys patagonicus

$\left(F_{2,146}=19.03 ; P_{(\text {perm })}<0.0001\right)$ and Jaccard similarity $\left(F_{2,146}=21.78 ; P_{\text {(perm) }}<0.0001\right)$. A posteriori tests underlined significant differences for most comparisons (all $P<0.001$ ); except for the pairs $X$. rasile- $P$. patagonicus using BrayCurtis index and $P$. isosceles $-P$. patagonicus using Jaccard index (both $P>0.05$ ).

Comparisons of the averaged infracommunity descriptors showed that $P$. isosceles harboured a higher number of parasites (Fig. 4a), but also a higher value of dominance (Fig. 4b) and the lowest diversity (Fig. 4c), whereas the species richness of $P$. patagonicus was notably higher than those of the other two host species (Fig. 4d).

After correcting for host size, all indices were significantly different between flounder species (Table 6), however pairwise tests showed that both Paralichthys species harboured similar values for all infracommunity descriptors, with $P$. patagonicus and $X$. rasile displaying also marginal differences in diversity. Multivariate dispersion of data could have an important influence on the significance of differences in total mean abundance involving $X$. rasile and, to a lesser extent, those of diversity between $P$. patagonicus and $X$. rasile (Table 6).

\section{Discussion}

Given the phylogenetic relatedness among the host species, the presence of shared parasites, either conspecific or phylogenetically related to each other, was expected as a result of their inheritance from their common ancestors. However, the identification of host-specific parasites showed that only $D$. pleuronectidis was shared by two flounders (the two Paralichthys spp.). This species was originally described from Paralichthys olivaceus (Temminck et Schlegel, 1846) in Toyama Bay in Japanese waters (Yamaguti 1935), although taking into account the geographical distance it is probably
Table 5 One-factor PERMANOVA results of infracommunity data of parasites of three species of flounders based on Bray-Curtis (for abundance) or Jaccard (for presenceabsence) dissimilarity measures with host length as covariable

$P$ values obtained after 9,999 permutations

\begin{tabular}{lllllll}
\hline Similarity measurement & Source & $d f$ & SS & MS & $F$ & $P_{\text {(perm) }}$ \\
\hline Bray-Curtis & Host length & 1 & 15,790 & 15,790 & 9.11 & $<0.0001$ \\
& Host species & 2 & $1.3181 \times 10^{5}$ & 65,904 & 38.03 & $<0.0001$ \\
& Host length $\times$ species & 2 & 10,620 & $5,310.1$ & 3.06 & $<0.01$ \\
& Residual & 143 & $2.4779 \times 10^{5}$ & $1,732.8$ & & \\
& Total & 148 & $4.0601 \times 10^{5}$ & & & \\
Jaccard & Host length & 1 & 45,589 & 45,589 & 39.01 & $<0.0001$ \\
& Host species & 2 & 35,661 & 17,831 & 15.26 & $<0.0001$ \\
& Host length $\times$ species & 2 & $7,104.9$ & $3,552.4$ & 3.04 & $<0.01$ \\
& Residual & 143 & $1.6714 \times 10^{5}$ & $1,168.8$ & & \\
& Total & 148 & $2.5549 \times 10^{5}$ & & & \\
\hline
\end{tabular}


a

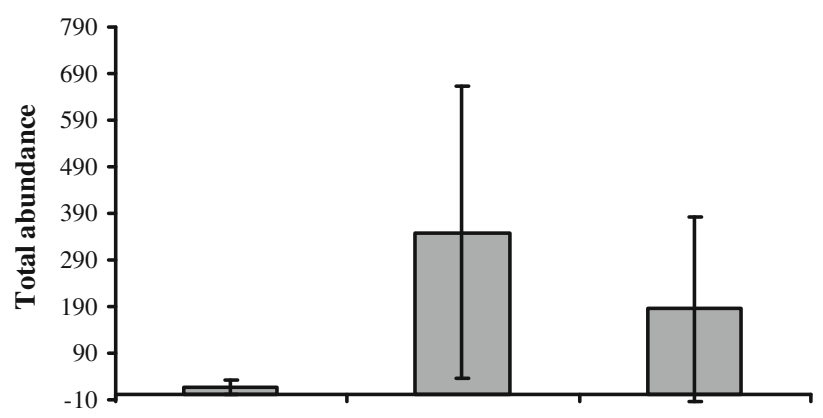

b

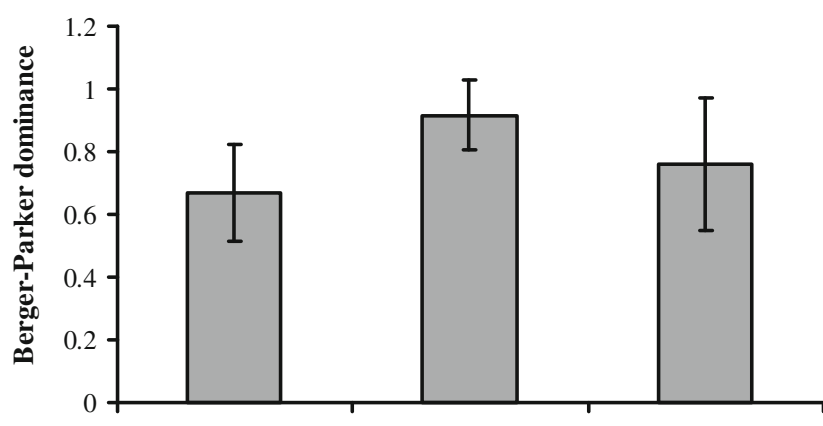

c

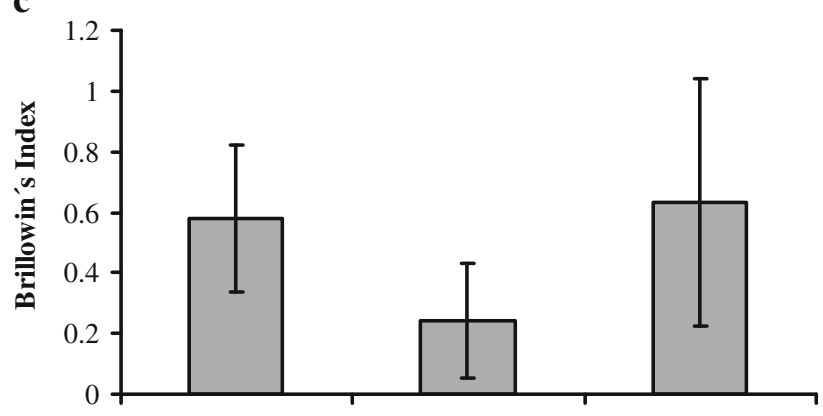

d

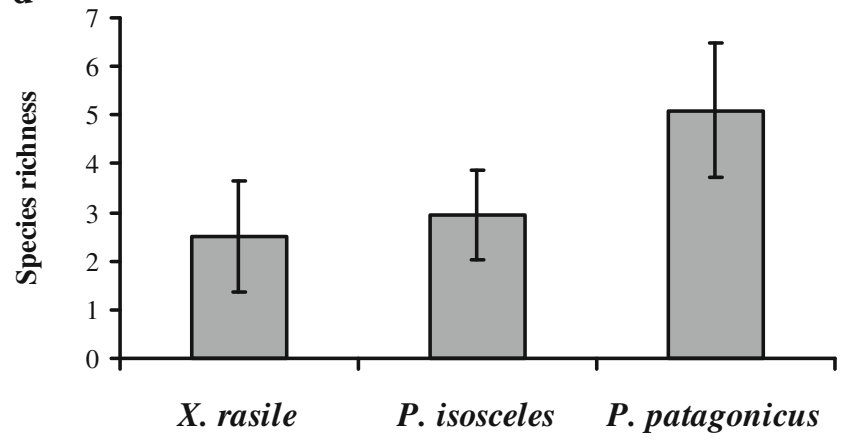

Fig. 4 Mean infracommunity descriptors in three species of paralichthyid flounders. a Total abundance, b dominance, c diversity, d richness

that they represent sibling species. Cucullanus bonaerensis was described from the Brazilian codling Urophycis brasiliensis (Gadiformes) in the same region (Lanfranchi et al. 2004), but none of the adult females from codling was found to be gravid suggesting the presence of this parasite constituted an accidental infection in an unsuitable host (Lanfranchi et al. 2004). The presence of gravid females of $C$. bonaerensis in $X$. rasile suggests that this is the definitive host for this nematode. The second species of Cucullanus found in this host was not identified, so no conclusions can be made on their specificity. Brasilochondria riograndensis, found on P. patagonicus, has also been recorded on the sympatric congener $P$. orbignyanus (Braicovich and Alarcos 2007), but not in P. isosceles. However, all host-specific parasites were of little importance as contributors to abundance and species richness in all three flounder species, as well as to similarity within and between host species. This group was not only irrelevant in delineating the repeatability of communities in each flounder species, but also in the structuring of parasite assemblages of all three species as a phylogenetically related group. Indeed, hostspecific parasites diminished similarity between infracommunities within host species and the only species shared by two flounder species contributed more to dissimilarity between them than other species present in only one of them.

Poulin et al. (2011), based on analyses of species richness, stressed that host phylogeny may often outweigh specific host ecological traits as a predictor of parasite species richness. This conclusion was based on extensive datasets, gathered at broad spatial scales and including both related and unrelated host species. On the other hand, the present study is in agreement with others dealing with phlylogenetically related hosts, in which analyses of either species richness or multivariate abundance data (Lile 1998; Muñoz et al. 2006; Marques et al. 2011) provide strong evidence that host phylogeny has only a weak influence on parasite diversity and community structure. Studies carried out at intermediate scales (unrelated hosts caught at short temporal and spatial scales) have concluded that both phylogeny and host ecology influence the composition of the parasite fauna of fishes (Aguirre-Macedo et al. 2007; Luque et al. 2004; Takemoto et al. 2005). The quantification of the relative influence of both host phylogeny and ecology as drivers of parasite diversity, as in many other fields of parasite ecology (see Poulin and Mouritsen 2003; Fredensborg et al. 2006; Krasnov et al. 2011), seems to be a matter of scale.

Similarity analyses based on abundances of nonspecific larval parasites showed that the highest homogeneity of infracommunities was displayed by the two congeneric host species. This pattern could be a consequence of their similar and high trophic level. It has been shown recently that fish species at a low trophic level harbour more variable and stochastic parasite assemblages than hosts at a higher trophic level, which display higher values of similarity between infracommunities (Timi et al. 2011). Indeed, flounders at a high trophic level harbour higher numbers of parasites, especially those that largely dominate the assemblages, homogenizing and increasing the quantitative similarities among conspecifics. 
Table 6 Comparisons of infracommunity descriptors (PERMANOVA) and their dispersions (PERMDISP) of unspecific non-intestinal parasite species in three sympatric paralichthyid flounders

\begin{tabular}{|c|c|c|c|c|c|c|c|c|c|c|}
\hline \multirow[t]{3}{*}{ Infracommunity Descriptors } & \multicolumn{5}{|c|}{ PERMANOVA } & \multicolumn{5}{|c|}{ PERMDISP } \\
\hline & \multicolumn{2}{|l|}{ Main test } & \multicolumn{3}{|c|}{ Pair-wise test $(P)$} & \multicolumn{2}{|c|}{ Main test } & \multicolumn{3}{|c|}{ Pair-wise test $(P)$} \\
\hline & Pseudo- $F$ & $P$ & $X r-P i$ & $X r-P p$ & $P i-P p$ & $F$ & $P$ & $X r-P i$ & $X r-P p$ & $P i-P p$ \\
\hline Total abundance & 28.37 & $<0.0001$ & $<0.0001$ & $<0.0001$ & $>0.05$ & 23.73 & $<0.0001$ & $<0.0001$ & $<0.0001$ & - \\
\hline Species richness & 16.27 & $<0.0001$ & 0.013 & $<0.0001$ & $>0.05$ & 6.07 & $<0.01$ & $>0.05$ & $>0.05$ & - \\
\hline Diversity & 11.59 & $<0.0001$ & $<0.0001$ & 0.041 & $>0.05$ & 19.82 & $<0.0001$ & $>0.05$ & $<0.001$ & - \\
\hline Dominance & 24.16 & $<0.0001$ & $<0.0001$ & $<0.001$ & $>0.05$ & 16.76 & $<0.0001$ & 0.017 & 0.013 & - \\
\hline
\end{tabular}

The higher similarity within samples of both Paralichthys spp., which occupy a higher position in the food web because of their ichthyophagous habits, can be due to the accumulation of larger numbers of infective stages acquired as packets of helminth species that travel together in paratenic fish hosts along food chains (Bush et al. 1993; Poulin and Valtonen 2001; Marcogliese 2002). X. rasile, on the other hand, displays impoverished assemblages, resulting from stochastic encounter events at low densities, which in turn decrease intraspecific similarity, reflecting the dilute nature of parasite distribution in previous intermediate invertebrate hosts (Marcogliese 1995, 2002).

It has been also postulated that juvenile fish harbour more variable and stochastic parasite communities than older fish (Timi et al. 2010b), which could explain the higher homogeneity between infracommunities of $P$. isosceles in comparison with $P$. patagonicus. It could be due to young fish beginning their lives free of parasites, followed by small differences in exposure to different parasites generating substantial differences between individuals. Over time, parasite communities become homogenized by repeated exposure. This pattern of increasing predictability in older fish has been observed in experimental fish, initially uninfected, and exposed to natural infections (Vidal-Martinez et al. 1998) as well as in wild fish (Timi et al. 2010b).

Comparisons across host species showed the highest quantitative similarity between $P$. isosceles and $P$. patagonicus, an expected result given the prevalence of $100 \%$ in both host species shown by $G$. carvajalregorum, the typical parasite of both Paralichthys spp., and the main contributor to within species similarity, although its abundance was also the main factor responsible for the differences between them. For $X$. rasile, on the other hand, this role was played by $C$. australe.

PERMANOVA analyses, after correcting for fish size, confirmed statistically that both Paralichthys spp. species harbour assemblages of similar structure, but that they also showed significant differences in composition when binary data were compared between infracommunities across host species. This is not surprising, as the Bray-Curtis index incorporates more information about each community, i.e., the abundance of each species as opposed to the binary data only, and is less subject to the vagaries of rare species than the Jaccard index.

Fish parasite communities in the northern Argentinean Sea are dominated by trophically transmitted larval parasites of low host-specificity (Timi 2007). Given the high abundances and broad distributions of these parasites in the regional compound community (Timi 2007; Timi and Lanfranchi 2009), which are obtained via passive sampling of available infective stages by feeding on previous intermediate hosts, the assemblages they form predictable subsets of the species available regionally. This applies to parasite assemblages in all host species so far examined in this region, with a non-random composition and a structure determined mainly by ecological filters, such as fish habitat or diet (Lanfranchi et al. 2009; Timi and Lanfranchi 2009; Rossin and Timi 2010; Timi et al. 2011). These parasites have such an influence that the infracommunities they form are governed by their abundances (Timi and Lanfranchi 2009). In fact, if a PERMANOVA is run including all parasite species found in the three flounder species, even the host-specific ones, and after correcting for flounder size, infracommunities of $P$. isosceles and $P$. patagonicus do not differ in their structure (unpublished data).

In the present study, the sympatry of the three flounder species and their benthic habits reduce the ecological filters and only the host traits can constrain the number of both species and individuals in their parasite assemblages to produce differences between fish species. Two fish species with different size, but exposed to the same pool of infective stages, should acquire qualitatively or quantitatively different parasite assemblages depending of the amount and type of prey they eat. Increasing differences in interspecific host characteristics should, therefore, lead to being exposed to increasingly different subsets of the total assemblage of parasite species, and similarity in parasite assemblages should decay as a function of trophic or size differences between fish species (Timi et al. 2010b). 
The sample of $P$. patagonicus was caught 16 months later than those of the other two flounders. However, and in despite temporal differences in the accumulation of larval helminths that can generate differences between fish species, the life spans of the selected larval parasites diminished the possible variability of community structure at this temporal scale. Host trophic level, therefore, emerged as the main explanatory variable for the differences observed at host generic level. Although it seems obvious, the present data explicitly show that two sympatric hosts with similar diets and habitats harbour parasite communities with identical structure. On the other hand, the size of flounders was the factor responsible for variation in parasite assemblages between congeneric hosts.

The effect of host size on the discrimination between the two Paralichthys spp. was clearly observed when the infracommunity descriptors were analyzed. Values of diversity depended on the balance between dominance and species richness. In fact, the higher number of parasites displayed by $P$. isosceles was almost exclusively due to the abundance of G. carvajalregorum (which represented near $92 \%$ of all parasite individuals found in this host); this parasite was also responsible for the higher dominance which, combined with the intermediate values of species richness produced the lowest diversity. The opposite trend was observed for $P$. patagonicus, which by displaying the highest species richness and intermediate values of dominance reached the maximum diversity. Finally, X. rasile with the lowest values of both species richness and dominance, displayed an intermediate diversity. These differences were confirmed by PERMANOVA analyses, but the correction for fish size showed that both Paralichthys species, if they were of comparable sizes, should harbour similar infracommunities. This similarity is a clear reflection of both the influence of fish size in drawing the differences between them and their shared trophic habits by comparison with $X$. rasile.

The higher species richness in P. patagonicus may be attributed to the larger size of specimens compared with the other two flounder species. Host size is a key determinant of parasite community structure across fish species (Luque and Poulin 2008) by affecting parasite diversity through its influence on the rates of parasite speciation and colonization by new parasites in evolutionary and ecological time scales, respectively. An increase in the number of species in larger hosts is a common feature of fish-parasite systems, because larger bodied hosts should be able to accommodate more parasite species and to sustain a greater absolute number of parasites than small ones. They also display larger surface areas for parasite attachment and ingest larger quantities of food with a concomitant higher exposure to infective stages (Guégan et al. 1992; Poulin 2000; Valtonen et al. 2010). Furthermore, large fish can also feed on larger prey, broadening the set of potential parasites (Timi et al. 2011). These results, therefore, imply that if specimens of $P$. isosceles were larger, they should harbour richer infracommunities.

On the other hand, the higher abundance observed in $P$. isosceles should imply that, if these fishes were larger they should have lower abundances than they actually have, an unexpected situation given the cumulative effect of host size on parasite burdens. This contradictory fact is, however, attributable to the age of specimens of $P$. isosceles, which were comparatively the oldest, judging by the percentage of the maximum length the species reached, and is a consequence of the dominance of long-lived larval stages in the assemblages. The intensity of parasite infections is known to increase with the age of fish hosts (Dogiel et al. 1958; Poulin 2000); therefore, older fish have had longer to accumulate parasites, by being exposed to parasites for longer periods than younger hosts.

In synthesis, both size and age act together as drivers of parasite community structure. This is a well-known feature of fish-parasite systems (Poulin 2000), which has been largely based on evidence from studies based on a single fish species. Because of the logical relationship between age and size, it has been generally assumed that both variables act synergistically, and the distinction between their individual outcomes is not undemanding. The present study, by analyzing comparatively two species harbouring parasite assemblages of equivalent structure, but with different age-size relationships, showed that both variables seem to act at dissimilar rates on different characteristics of parasite assemblages. Indeed, fish age affects mainly the parasite abundance, whereas body size influences mainly the species richness, through its relationship with the trophic level. The discernment between these variables is essential not only for understanding how parasite community structure is mediated by size-dependent trophic interactions, but also for assessing how much this structure is affected by the host age.

Acknowledgements The authors thank Mr. Roque Bruno from Santa Cecilia fish market and Mr. Jorge Ricci, Necochea, for kindly providing fish samples. We also thank Dr. K. MacKenzie (School of Biological Sciences, University of Aberdeen, Aberdeen, Scotland, UK) for his valuable suggestions on the manuscript. Financial support was provided by grants from CONICET (PIP 112-200801-00024), FONCyT (PICT 02199/07) and Universidad Nacional de Mar del Plata (EXA 531/10).

\section{References}

Aguirre-Macedo ML, Vidal-Martínez VM, González-Solís D, Caballero PI (2007) Helminth communities of four commercially important fish species from Chetumal Bay, Mexico. J Helminthol 81:19-31

Alarcos AJ, Timi JT (2011) A new species of Acanthochondria (Copepoda: Chondracanthidae) parasitizing the flounder Xystreurys rasile (Pleuronectiformes: Paralichthyidae) from Argentina. Folia Parasitol 58:164-168 
Anderson MJ, Gorley RN, Clarke KR (2008) PERMANOVA+for PRIMER: guide to software and statistical methods. PRIMER-E, Plymouth

Bagge AM, Poulin R, Valtonen ET (2004) Fish population size, and not density, as the determining factor of parasite infection: a case study. Parasitology 128:305-313

Braicovich PE, Alarcos AJ (2007) Redescription of Brasilochondria riograndensis (Copepoda: Chondracanthidae) parasitic on flounder, Paralichthys orbignyanus (Actinopterygii: Pleuronectiformes) from South American Atlantic waters. Acta Parasitol $52: 273-277$

Bush AO, Heard RW, Overstreet RM (1993) Intermediate hosts as source communities. Can J Zool 71:1358-1363

Bush AO, Lafferty KD, Lotz JM, Shostak AW (1997) Parasitology meets ecology on its own terms: Margolis et al. revisited. J Parasitol 83:575-583

Clarke KR (1993) Non-parametric multivariate analyses of changes in community structure. Aust J Ecol 18:117-143

Clarke KR, Gorley RN (2006) PRIMER V6: User manual/tutorial. PRIMER-E, Plymouth

Clarke KR, Warwick RM (2001) Change in marine communities: an approach to statistical analysis and interpretation, 2nd edn. PRIMER-E, Plymouth

Cousseau MB, Perrotta R (2004) Peces marinos de Argentina: biología, distribución, pesca. INIDEP, Mar del Plata

Desdevises Y, Legendre P, Azouzi L, Morand S (2003) Quantifying phylogenetically structured environmental variation. Evolution 57:2647-2652

Díaz de Astarloa JM, Munroe TA (1998) Systematics, distribution and ecology of commercially important paralichthyid flounders occurring in Argentinean-Uruguayan waters (Paralichthys, Paralichthydae): an overview. J Sea Res 39:1-9

Dogiel VA, Petrushevski GK, Polyanski YI (1958) Parasitology of Fishes. Oliver and Boyd, London (Translated from Russian by Z. Kabata, 1961)

Felizardo NN, Knoff M, Pinto RM, Gomes DC (2009a) Larval anisakid nematodes of the flounder, Paralichthys isosceles Jordan, 1890 (Pisces: Teleostei) from Brazil. Neotrop Helminthol 3:57-64

Felizardo NN, Menezes RC, Tortelly R, Knoff M, Pinto RM, Gomes DC (2009b) Larvae of Hysterothylacium sp. (Nematoda: Anisakidae) in the sole fish Paralichthys isosceles Jordan, 1890 (Pisces: Teleostei) from the littoral of the state of Rio de Janeiro, Brazil. Vet Parasitol 166:175-177

Felizardo NN, Lopes Torres EJ, Gonçalves Fonseca MC, Magalhães Pinto R, Corrêa Gomes D, Knoff M (2010) Cestodes of the flounder Paralichthys isosceles Jordan, 1890 (Osteichthyes-Paralichthyidae) from the State of Rio de Janeiro, Brazil. Neotrop Helminthol $4: 113-126$

Felizardo NN, Justo MC, Knoff M, Fonseca MCG, Pinto RM, Gomes DC (2011) Juvenile didymozoids of the types, Torticaecum and Neotorticaecum (Didymozoidae: Digenea), from new marine fish hosts (Pisces: Teleostei) in the neotropical region of Brazil. J Helminthol 3:270-275

Fredensborg BL, Mouritsen KN, Poulin R (2006) Relating bird host distribution and spatial heterogeneity in trematode infections in an intertidal snail: from small to large scale. Mar Biol 149:275-283

Guégan J-F, Lambert A, Lévêque C, Combes C, Euzet L (1992) Can host body size explain the parasite species richness in tropical freshwater fishes? Oecologia 90:197-204

Incorvaia IS, Díaz de Astarloa JM (1998) Estudio preliminar de las larvas (Nematoda: Ascaridida) parásito de Paralichthys orbignyanus (Valenciennes, 1839) y Paralichthys patagonicus (Pisces: Pleuronectiformes). Bol Chil Parasitol 53:38-42

Krasnov BR, Poulin R, Mouillot D (2011) Scale-dependence of phylogenetic signal in ecological traits of ectoparasites. Ecography $34: 114-122$
Lanfranchi AL, Timi JT, Sardella NH (2004) Cucullanus bonaerensis n. sp. (Nematoda: Cucullanidae) parasitizing Urophycis brasiliensis (Pisces: Phycidae) from Argentinean waters. J Parasitol 90:808-812

Lanfranchi AL, Rossin MA, Timi JT (2009) Parasite infracommunities of a specialised marine fish species in a compound community dominated by generalist parasites. J Helminthol 83:373-378

Lester RJG, MacKenzie K (2009) The use and abuse of parasites as stock markers for fish. Fish Res 97:1-2

Lile NK (1998) Alimentary tract helminths of tour pleuronectid flatfish in relation to host phylogeny and ecology. J Fish Biol 53:945-950

Luque JL, Poulin R (2008) Linking ecology with parasite diversity in Neotropical fishes. J Fish Biol 72:189-204

Luque JL, Tavares LER (2007) Checklist of Copepoda associated with fishes from Brazil. Zootaxa 1579:1-39

Luque JL, Mouillot D, Poulin R (2004) Parasite biodiversity and its determinants in coastal marine teleost fishes of Brazil. Parasitology 128:671-682

Magurran AE (1988) Ecological diversity and its measurement. Princeton University Press, Princeton

Marcogliese DJ (1995) The role of zooplankton in the transmission of helminth parasites to fish. Rev Fish Biol Fish 5:336-371

Marcogliese DJ (2001) Pursuing parasites up the food chain: implications of food web structure and function on parasite communities in aquatic systems. Acta Parasitol 46:82-93

Marcogliese DJ (2002) Food webs and the transmission of parasites to marine fish. Parasitology 124:83-99

Marques JF, Santos MJ, Teixeira CM, Batista MI, Cabral HN (2011) Host-parasite relationships in flatfish (Pleuronectiformes) - the relative importante of host biology, ecology and phylogeny. Parasitology 138:107-121

Morand S, Poulin R (2003) Phylogenies, the comparative method and parasite evolutionary ecology. Adv Parasitol 54:281-302

Muñoz G, Grutter AS, Cribb TH (2006) Endoparasite communities of five fish species (Labridae: Cheilininae) from Lizard Island: how important is the ecology and phylogeny of the hosts? Parasitology 132:363-374

Pérez-del Olmo A, Fernández M, Raga JA, Kostadinova A, Poulin R (2008) Halfway up the trophic chain: development of parasite communities in the sparid fish Boops boops. Parasitology 135:257-268

Poulin R (1995) Phylogeny, ecology, and the richness of parasite communities in vertebrates. Ecol Monogr 65:283-302

Poulin R (2000) Variation in the intraspecific relationship between fish length and intensity of parasitic infection: biological and statistical causes. J Fish Biol 56:123-137

Poulin R (2007) Are there general laws in parasite ecology? Parasitology 134:763-776

Poulin R, Morand S (2000) The diversity of parasites. Q Rev Biol $75: 277-293$

Poulin R, Morand S (2004) Parasite biodiversity. Smithsonian Institution Press, Washington, DC

Poulin R, Mouritsen KN (2003) Large-scale determinants of trematode infections in intertidal gastropods. Mar Ecol Progr Ser 254:187-198

Poulin R, Rohde K (1997) Comparing the richnessof metazoan ectoparasite communities of marine fishes: controlling for host phylogeny. Oecologia 110:278-283

Poulin R, Valtonen ET (2001) Interspecific associations among larval helminths in fish. Int J Parasitol 31:1589-1596

Poulin R, Guilhaumon F, Randhawa HS, Luque JL, Mouillot D (2011) Identifying hotspots of parasite diversity from species-area relationships: host phylogeny versus host ecology. Oikos 120:740-747

Rossin MA, Timi JT (2010) Parasite assemblages of Nemadactylus bergi (Pisces: Latridae): the role of larval stages in the short-scale predictability. Parasitol Res 107:1373-1379 
Sasal P, Morand S, Guégan J-F (1997) Determinants of parasite species richness in Mediterranean marine fish. Mar Ecol Prog Ser 149:61-71

Suriano DM, Labriola JB (1998) Redescription of Anonchocephalus chilensis (Riggenbach, 1896) (Pseudophyllidea: Triaenophoridae) and description of A. patagonicus n. sp. Bol Chil Parasitol 53:73-77

Suriano DM, Labriola JB (1999) Diclidophoroides maccallumi Price, 1943 and Neoheterobothrium paralichthyi sp. n. (Monogenea, Diclidophoridae), parasites of fishes (Gadiformes and Pleuronectiformes) from the southwestern Atlantic Ocean. Acta Parasitol 44:160-164

Szidat L (1961) Versuch einer Zoogeographie des Süd-Atlantik mit Hilfe von Leitparasiten der Meeresfische. Parasitol Schrif 13:1-98

Takemoto RM, Pavanelli G, Lizama MAP, Luque JL, Poulin R (2005) Host population density as the major determinant of endoparasite species richness in floodplain fishes of the upper Parana River, Brazil. J Helminthol 79:75-84

Timi JT (2007) Parasites as biological tags for stock discrimination in marine fish from South American Atlantic waters. J Helminthol $81: 107-111$

Timi JT, Lanfranchi AL (2009) The importance of the compound community on the parasite infracommunity structure in a small benthic fish. Parasitol Res 104:295-302

Timi JT, Lanfranchi AL, Luque JL (2010a) Similarity in parasite communities of the teleost fish Pinguipes brasilianus in the southwestern Atlantic: infracommunities as a tool to detect geographical patterns. Int J Parasitol 40:243-254

Timi JT, Luque JL, Poulin R (2010b) Host ontogeny and the temporal decay of similarity in parasite communities of marine fish. Int $\mathrm{J}$ Parasitol 40:963-968

Timi JT, Rossin MA, Alarcos AJ, Braicovich PE, Cantatore DMP, Lanfranchi AL (2011) Fish trophic level and the similarity of larval parasite assemblages. Int J Parasitol 41:309-316

Vales DG, García NA, Crespo EA, Timi JT (2011) Parasites of a marine benthic fish in the Southwestern Atlantic: searching for geographical recurrent patterns of community structure. Parasitol Res 128:261-272

Valtonen ET, Marcogliese DJ, Julkunen M (2010) Vertebrate diets derived from trophically transmitted fish parasites in the Bothnian Bay. Oecologia 162:139-152

Vickery WL, Poulin R (1998) Parasite extinction and colonization, and the evolution of parasite communities: a simulation study. Int $\mathbf{J}$ Parasitol 28:727-737

Vidal-Martinez VM, Kennedy CR, Aguirre-Macedo ML (1998) The structuring process of the macroparasite community of an experimental population of Cichlasoma urophthalmus through time. $\mathrm{J}$ Helminthol 72:199-207

Yamaguti S (1935) Studies of the helminth fauna of Japan, part 9: I. Nematodes of fishes. Jpn J Zool 6:384-385

Zar JH (1996) Biostatistical analysis. Prentice-Hall, Upper Saddle River, NJ 